\title{
THE NEW NAGOYA RADIOCARBON LABORATORY
}

\author{
YASUSHI MURAKI, GRANT KOCHAROV, ${ }^{1}$ TOORU NISHIYAMA, YUKIKO NARUSE, \\ TAKUYA MURATA, KIMIAKI MASUDA and Kh. A. ARSLANOV?
}

Solar-Terrestrial Environment Laboratory, Nagoya University, Chikusa-ku, Nagoya 464-01, Japan

ABSTRACT. A liquid scintillation counting apparatus that enables highly accurate measurements of ${ }^{14} \mathrm{C}$ has been constructed at the Solar-Terrestrial Environment Laboratory, Nagoya University. The main aim of the project is high precision year-by-year measurements of the ${ }^{14} \mathrm{C}$ content in tree rings of an old cedar tree from Yaku Island, Japan. We present the results of ${ }^{14} \mathrm{C}$ measurements on tree rings from the Agematsu region for recent decades to confirm the validity of the system.

\section{INTRODUCTION}

The cosmic ray group of the Solar-Terrestrial Environment Laboratory (STEL) at Nagoya University has plans to measure the year-by-year solar activity, over a 2000 -yr period, based on radiocarbon measurements on Japanese Yaku cedar trees. Previously, Kocharov et al. (1995) and Stuiver and Braziunas (1993) found that, during the solar activity minimum known as the Maunder Minimum, solar activity was not null but followed a $c a$. 22-yr periodicity, in contrast to the normal 11-yr cycle of solar activity. The Maunder Minimum is usually interpreted as a period of global cold climate, although this has not yet been accepted by the meteorological community. In order to carry out the study described above including other periods of minima (the Spörer and the Wolf Minima), and to determine whether or not solar activity really plays important role in climatic phenomena, we have developed our own ${ }^{14} \mathrm{C}$ counting system based on the liquid scintillation method for precise measurements. In this paper we report the construction of our system and the results of the first measurement of recent tree rings showing the bomb effect.

\section{METHODS}

When we planned the project mentioned above a few years ago, the accelerator mass spectroscopy (AMS) facility of Nagoya University did not yet have enough accuracy for precise measurements of radiocarbon in tree rings. So we decided to use a method developed in Russia that uses a large amount of liquid scintillator. Hopefully, the Nagoya facility will soon (end of 1997) have a new AMS with an accuracy of $0.3 \%$ (Nakamura 1997), but sharing machine time will be a problem.

An appropriate system must produce a large amount of benzene $(\sim 10 \mathrm{~mL})$ at once and must also have several detectors to enable many sample measurements to be made in parallel. We must prepare several benzene synthesizing systems and ${ }^{14} \mathrm{C}$ measurement systems under a limited budget, without losing stability and accuracy. Our benzene synthesizing system is based on a method developed at the Geographical Research Institute of St. Petersburg University (Arslanov 1987; Arslanov, Tertychnaya and Chernov 1993).

\section{Sample Pretreatment and Benzene Synthesis System}

Sliced tree-ring samples were extracted for $6 \mathrm{~h}$ with a benzene-ethyl alcohol mixture (in a $1: 1$ proportion) in the Soxhlet apparatus to remove resin and dried in a vacuum oven at $105^{\circ} \mathrm{C}$ for $90 \mathrm{~min}$.

\footnotetext{
${ }^{1}$ Present address: A. F. Ioffe Institute of Physics and Technology, Russian Academy of Science, St. Petersburg 194021, Russia

${ }^{2}$ On leave from Geographical Research Institute of St. Petersburg University, St. Petersburg 199004, Russia
}

Proceedings of the 16th International ${ }^{14} \mathrm{C}$ Conference, edited by W. G. Mook and J. van der Plicht

RADIOCARBON, Vol. 40, No. 1, 1998, P. 177-182 
Then the samples were immersed in hot $\left(80^{\circ} \mathrm{C}\right) 1 \% \mathrm{NaOH}$ and $1 \% \mathrm{HCl}$ solutions for $30 \mathrm{~min}$, respectively, washed with distilled water and dried for $10 \mathrm{~h}$ at $105^{\circ} \mathrm{C}$.

We chose the method of lithium carbide $\left(\mathrm{Li}_{2} \mathrm{C}_{2}\right)$ synthesis based on charcoal samples. To produce charcoal, the pretreated tree-ring samples are heated up to $600^{\circ} \mathrm{C}$ for $30 \mathrm{~min}$ in a stainless-steel container without supplying fresh air. Then coarse-grained charcoal reacts with lithium pellets $(10 \% \mathrm{Li}$ excess) at $800^{\circ} \mathrm{C}$ for $1 \mathrm{~h}$ in an evacuated stainless-steel reactor.

The acetylene production and benzene synthesis was carried out using the system shown in Figure 1. Acetylene gas $\left(\mathrm{C}_{2} \mathrm{H}_{2}\right)$ was produced by dripping distilled water inside the vessel containing $\mathrm{Li}_{2} \mathrm{C}_{2}$ after evacuating. The acetylene gas was purified with a solution of $\mathrm{CuCl}_{2}+\mathrm{FeCl}_{3}+\mathrm{H}_{2} \mathrm{SO}_{4}$, dried with $\mathrm{KOH}$ pellets and accumulated in glass containers with a volume of $10 \mathrm{~L}$, a production process requiring several hours. Then, the acetylene gas was transferred to a Pyrex ${ }^{\circledR}$ glass vessel containing catalyst pellets, through a column of $\mathrm{KOH}$ pellets and $\mathrm{P}_{2} \mathrm{O}_{5}$ mixed with glass fiber for drying the gas. The acetylene was converted to benzene in the vessel with the $\mathrm{V}_{2} \mathrm{O}_{5} \cdot \mathrm{Al}_{2} \mathrm{O}_{3} \cdot \mathrm{SiO}_{2}$ catalyst (Arslanov, Tertychnaya and Chernov 1993; Enerson et al. 1998), which allows production of highpurity benzene at room temperature with a yield $>90 \%$. The resulting benzene was distilled by means of vacuum sublimation.

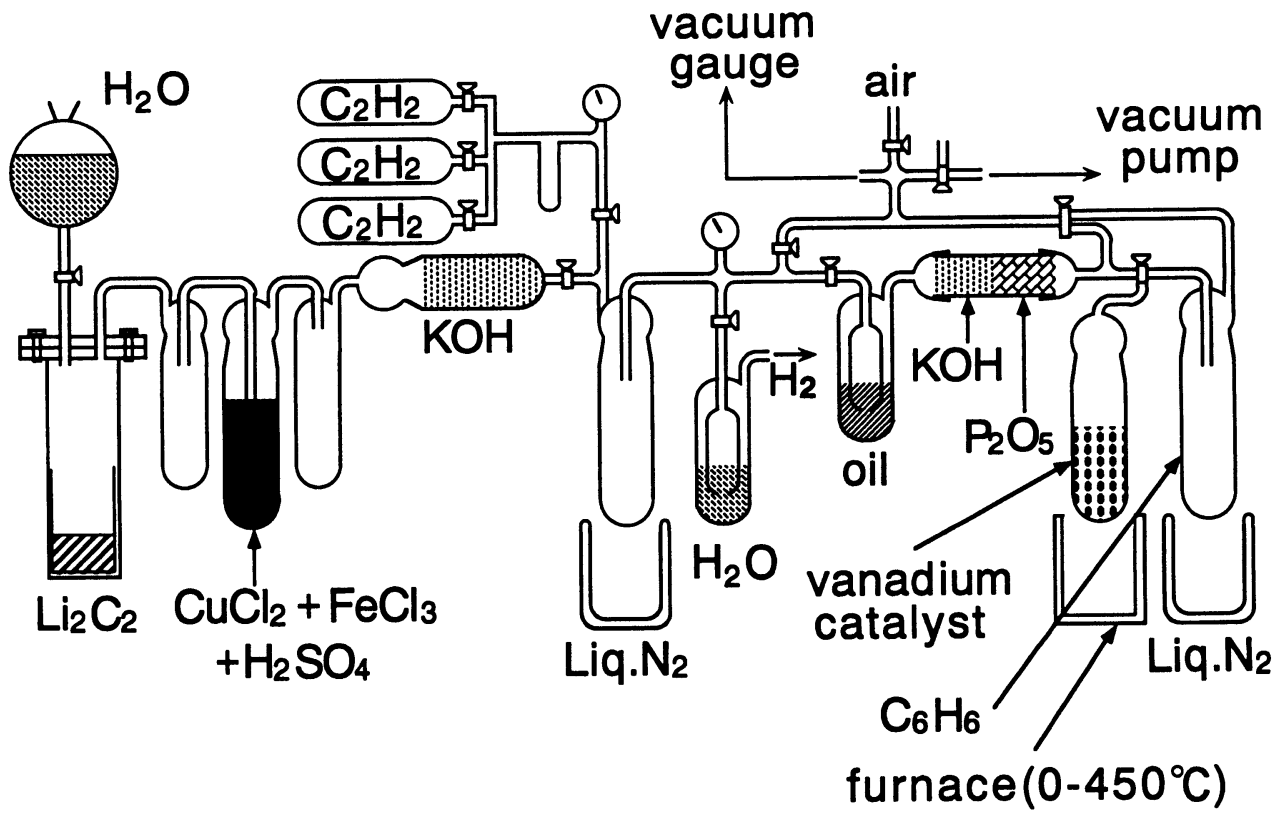

Fig. 1. Schematic diagram of installation for acetylene and benzene synthesis

We rendered the benzene into liquid scintillator by adding 2,5-diphenyloxazole (PPO) and POPOP in concentrations of $4 \mathrm{~g} \mathrm{~L}^{-1}$ and $0.1 \mathrm{~g} \mathrm{~L}^{-1}$, respectively. The liquid scintillator is poured into a cylindrical Teflon ${ }^{\circledR}$ vial.

\section{Radiocarbon Counting System}

A coincidence scintillation counter system developed at STEL during $1995-1996$ is used for ${ }^{14} \mathrm{C}$ measurements. The apparatus includes two independent measuring systems, each of which consists of two 3-inch photomultipliers (Hamamatsu R594, S1/S2 and S3/S4) for samples and two 5-inch 
photomultipliers (Hamamatsu R1512, A1/A2 and A3/A4) coupled to a plastic scintillator for anticoincidence measurements, separated by shielding (Fig. 2). Such a system permits simultaneous measurement of two different samples. Two vials are located between the two 3-inch photomultipliers to increase the sample volume for high-precision measurement. The anticoincidence system surrounds the complete inner system ( $4 \pi$ geometry). This system rejects cosmic ray background and reduces the natural background. The massive shield box consists of iron with a thickness of $1 \mathrm{~cm}$, lead with a thickness of $5 \mathrm{~cm}$ and oxygen-free high-conductivity copper (OFHC) plates with a thickness of $5 \mathrm{~mm}$. The OFHC is installed to absorb X-rays and soft $\gamma$-rays from the lead blocks.

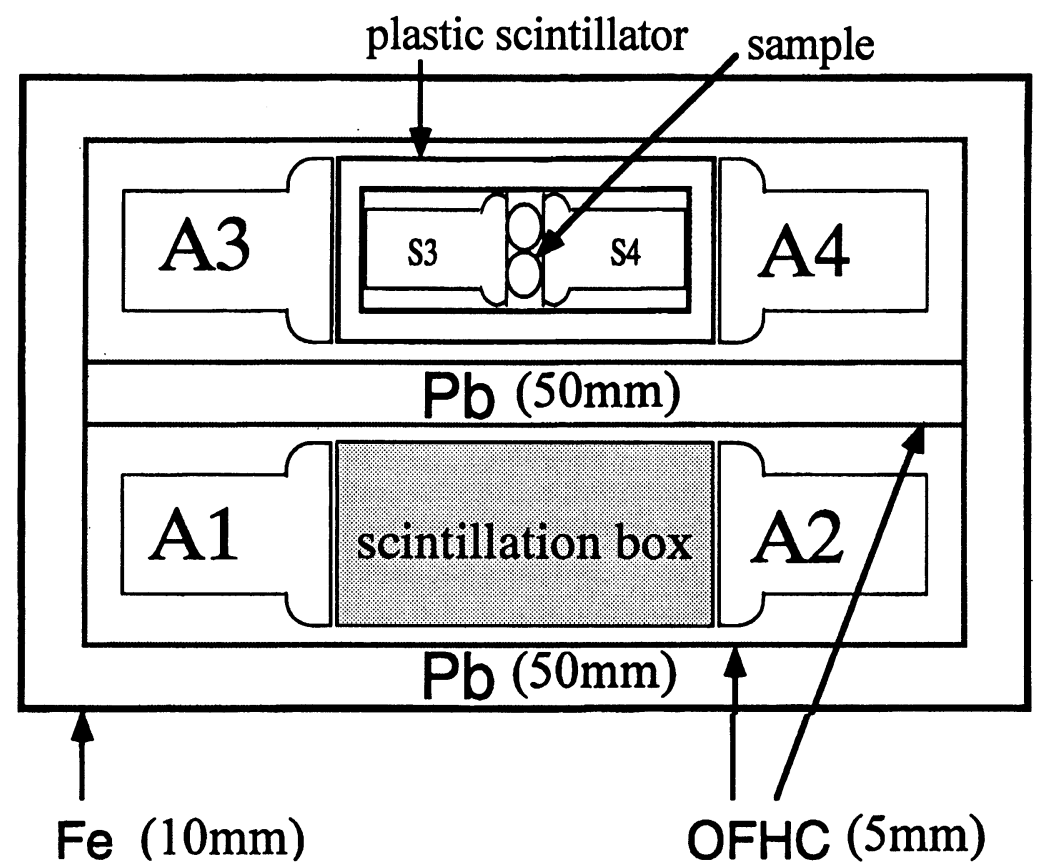

Fig. 2. Scintillation detector system for ${ }^{14} \mathrm{C}$ measurements. A1-A4: photomultipliers for anticoincidence; S3-S4: photomultipliers for ${ }^{14} \mathrm{C}$ counting

The individual pulse height from each photomultiplier is measured by an analog-to-digital converter (ADC) module (LeCroy $2249 \mathrm{~W}$ operated by a CAMAC system) and recorded in a computer. The output pulses of the photomultipliers are amplified using an amplifier (EG\&G ORTEC FTA820) that has a typical gain of 200. One signal of the two outputs is sent to an ADC and the other is used for making a trigger pulse after coincidence of both photomultiplier signals. As shown in Figure 3, our system can record pulse heights of ${ }^{14} \mathrm{C}$ decay electron signals with an efficiency as high as $65 \%$. Our counting room is shielded against electric noise. The detector is located inside an air-conditioned room. The gain variation with temperature is about $0.1 \%$ per ${ }^{\circ} \mathrm{C}$.

\section{RESULTS AND DISCUSSION}

As the first experiment with our system, we measured the bomb effect using annual pine tree samples collected from the Agematsu region ( $100 \mathrm{~km}$ northeast of Nagoya, elevation $1000 \mathrm{~m}$ above sea level). As shown in Figure 4 and Table 1, the bomb effect is clearly observed by our system. We also measured the same samples at the St. Petersburg University Radiocarbon Laboratory for some single-year rings (1963-1967), obtaining nearly identical results. In addition, 2-yr samples of a pine 


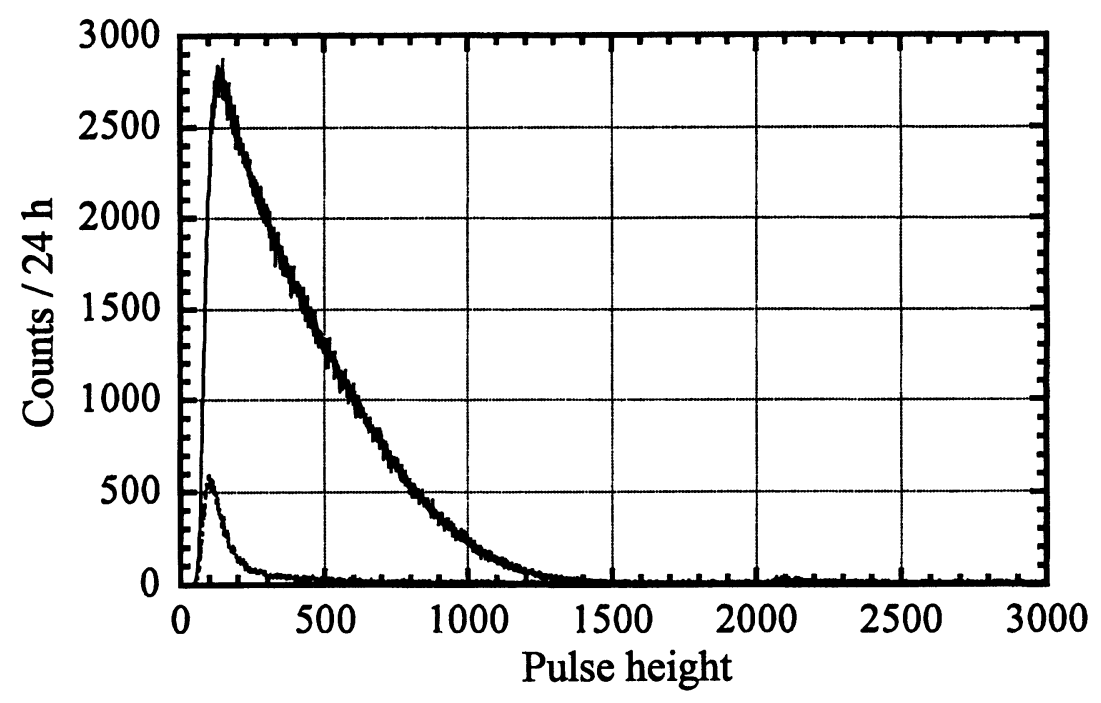

Fig. 3. Beta-ray spectrum of 5 -fold ${ }^{14} \mathrm{C}$ benzene standard and background spectrum of dead benzene

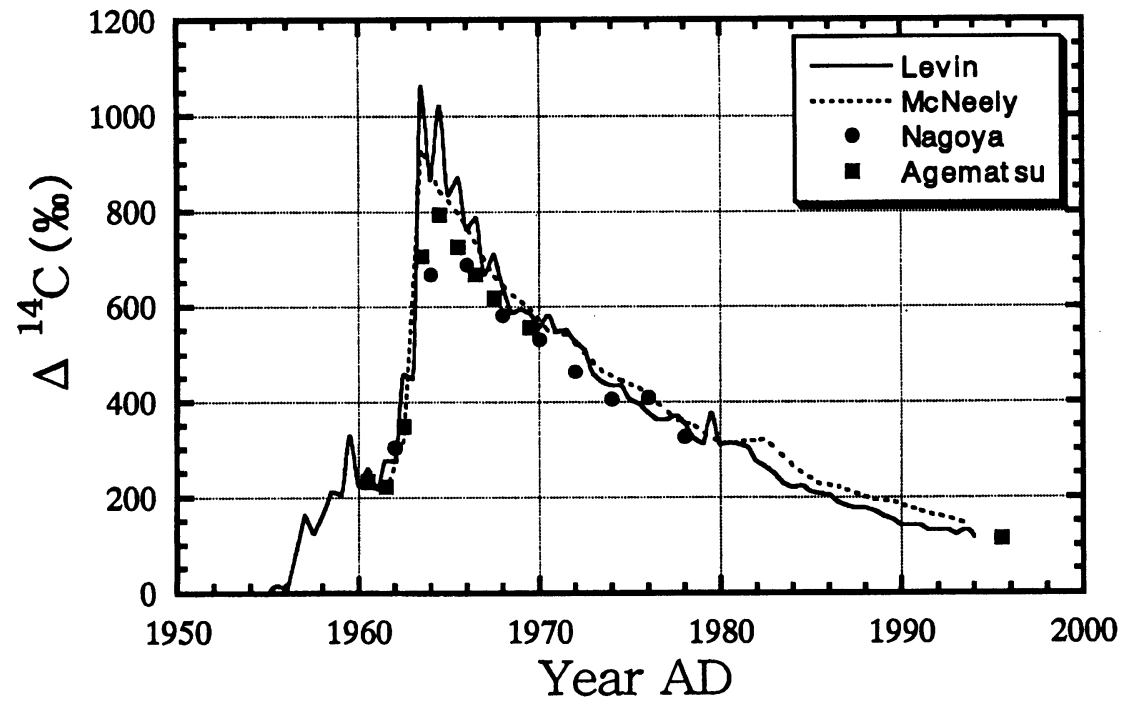

Fig. $4 .{ }^{14} \mathrm{C}$ measurements on Agematsu region pine tree rings and Nagoya pine tree rings. The continuous curves represent the data for the atmospheric samples (Levin, Münnich and Weiss 1980; Levin, Graul and Trivett 1995) and the data for maple leaves near Ottawa (McNeely 1994).

tree from the vicinity of Nagoya University was measured at St. Petersburg Radiocarbon Laboratory for intercomparison. The results are consistent with those of single-year rings from Agematsu.

We have plotted the data obtained by Levin, Graul and Trivett (1995) for atmospheric $\mathrm{CO}_{2}$ and McNeely (1994) for maple leaves for comparison. Our results are also consistent with other measurements for tree rings (e.g., Nakamura et al. 1987; Dai, Qian and Fan 1992). 
TABLE $1 .{ }^{14} \mathrm{C}$ Measurements on Japanese Tree-

Ring Samples, AD 1960-1995

\begin{tabular}{lcc}
\hline Lab code* & Year AD & \multicolumn{1}{c}{$\left.\Delta^{14} \mathrm{C}(\%)\right)$} \\
\hline \multicolumn{3}{l}{ Agematsu pine rings } \\
UN-10 & 1960 & $232.3 \pm 5.0$ \\
UN-9 & 1961 & $222.7 \pm 5.8$ \\
UN-8 & 1962 & $349.5 \pm 3.7$ \\
UN-7 & 1963 & $706.3 \pm 3.2$ \\
UN-6 & 1964 & $794.1 \pm 3.9$ \\
UN-5 & 1965 & $726.5 \pm 6.4$ \\
UN-4 & 1966 & $668.3 \pm 4.2$ \\
UN-3 & 1967 & $618.6 \pm 2.6$ \\
UN-2 & 1969 & $556.7 \pm 3.4$ \\
UN-1 & 1995 & $114.5 \pm 3.9$ \\
Nagoya pine rings & & \\
LU-3716 & $1961-1962$ & $304.8 \pm 7.3$ \\
LU-3744 & $1963-1964$ & $668.4 \pm 11.2$ \\
LU-3745 & $1965-1966$ & $689.2 \pm 10.6$ \\
LU-3746 & $1967-1968$ & $582.4 \pm 9.9$ \\
LU-3747 & $1969-1970$ & $531.3 \pm 9.8$ \\
LU-3748 & $1971-1972$ & $464.5 \pm 8.7$ \\
LU-3749 & $1973-1974$ & $405.5 \pm 7.5$ \\
LU-3750 & $1975-1976$ & $409.6 \pm 9.1$ \\
LU-3751 & $1977-1978$ & $326.5 \pm 9.3$ \\
\hline *UN = STEL, Nagoya University Radiocarbon Laboratory; \\
LU = St. Petersburg University Radiocarbon Laboratory
\end{tabular}

The results show that the maximum ${ }^{14} \mathrm{C}$ excess in tree rings from the Agematsu region $\left(\Delta^{14} \mathrm{C} \approx\right.$ $800 \%$ ) occurred in 1964, whereas the maximum excess in biosphere and atmosphere at the polar and middle latitudes of the Northern Hemisphere $\left(\Delta^{14} \mathrm{C} \sim 900-1050 \%\right)$ was observed during 1963 and 1964 (Levin, Münnich and Weiss 1980; McNeely 1994). Disparities in time and amplitude may be attributed to differences in vertical and horizontal mixing rates both within and between the troposphere and the stratosphere, and also to differences in the carbon dioxide exchange rate between the atmosphere and sea at different latitudes.

Reduction of ${ }^{14} \mathrm{C}$ excess in Agematsu tree-rings is seen between 1965 and 1995 and is consistent with an exponential decay. The ${ }^{14} \mathrm{C}$ excess of Agematsu tree-rings for 1995 amounts to $115 \%$. This figure is also consistent with the ${ }^{14} \mathrm{C}$ excess of atmospheric $\mathrm{CO}_{2}(=120 \%)$ for the whole of 1995 at Schauinsland station, Germany (Levin and Kromer 1997).

\section{Conclusion}

The chemical system developed at STEL allows us to produce an amount of benzene (10-15 mL) at once that is large enough for precise ${ }^{14} \mathrm{C}$ measurements of tree-ring samples. The validity of the chemical and ${ }^{14} \mathrm{C}$-counting techniques employed at STEL was confirmed by ${ }^{14} \mathrm{C}$ measurements of Japanese tree-ring samples formed between AD 1960 and 1995. 


\section{REFERENCES}

Arslanov, Kh. A. 1987 Radiocarbon: Geochemistry and Geochronology. Leningrad, Leningrad University Press: 300 p. (in Russian).

Arslanov, Kh. A., Tertychnaya, T. V. and Chernov, S. B. 1993 Problems and methods of dating low-activity samples by liquid scintillation counting. Radiocarbon 35(3): 393-398.

Dai, K.-M., Qian, Y. and Fan, C. Y. 1992 Bomb-produced ${ }^{14} \mathrm{C}$ in tree rings. In Long, A. and $\mathrm{Kra}, \mathrm{R}$. S., eds., Proceedings of the 14 th International ${ }^{14} \mathrm{C}$ Conference. $\mathrm{Ra}$ diocarbon 34(3): 753-756.

Enerson, T. B., Haas, H., Zarrabi, K. and Titus, R. L. 1998 Comparison of vanadium oxide catalysts for synthesis of benzene: Benzene purity, yields and reconditioning methods. Radiocarbon, this issue.

Kocharov, G. E., Ostryakov, V. M., Peristykh, A. N. and Vasiliev, V. A. 1995 Radiocarbon content variations and Maunder minimum of solar activity. Solar Physics 159: 381-391.

Levin, I., Graul, K. and Trivett, N. B. A. 1995 Long-term observations of atmospheric $\mathrm{CO}_{2}$ and carbon isotopes at continental sites in Germany. Tellus 47B: 23-34.
Levin, I. and Kromer, B. 1997 Twenty years of high-precision atmospheric ${ }^{14} \mathrm{CO}_{2}$ observations at Schauinsland station, Germany. Radiocarbon 39(2): 205-218.

Levin, I., Münnich, K. O. and Weiss, W. 1980 The effect of anthropogenic $\mathrm{CO}_{2}$ and ${ }^{14} \mathrm{C}$ sources on the distribution of ${ }^{14} \mathrm{C}$ in the atmosphere. In Stuiver, M. and $\mathrm{Kra}$, R. S., eds, Proceedings of the 10th International ${ }^{14} \mathrm{C}$ Conference. Radiocarbon 22(2): 379-391.

McNeely, R. 1994 Long-term environmental monitoring of ${ }^{14} \mathrm{C}$ levels in the Ottawa region. Environment International 20: 675-679.

Nakamura, T. 1997 Performance of the second-generation Tandetron AMS and its usage for researches. Summaries of Researches Using AMS at Nagoya, Dating and Materials Research Center, Nagoya University 8: 5-16.

Nakamura, T., Nakai, N., Kimura, M., Ohishi, S., Hattori, $\mathrm{Y}$. and Kikata, Y. 1987 Variation of ${ }^{14} \mathrm{C}$ concentration in tree rings (1945-1983). Geochemistry 21: 7-12.

Stuiver, M. and Braziunas, T. F. 1993 Sun, ocean, climate and atmospheric ${ }^{14} \mathrm{CO}_{2}$ : An evaluation of causal and spectral relationships. The Holocene 3: 289-305. 